\title{
Prediction for CUI in Piping Systems using Fuzzy Logic with Sensitivity Analysis of Corrosion Producing Factors
}

\author{
Muhammad Mohsin Khan ${ }^{1}$, Ainul Akmar Mokhtar ${ }^{1, *}$, Hilmi Hussin ${ }^{1}$, Masdi Muhammad ${ }^{1}$ \\ ${ }^{1}$ Mechanical Engineering Department, Universiti Teknologi Petronas, 32610 Bandar Seri Iskandar, \\ Perak, Malaysia
}

\begin{abstract}
Corrosion under insulation (CUI) is a progressive problem for piping systems in oil and gas industries especially in petrochemical and chemical plants due to its catastrophic disasters and consequently its automatic impact on the environment. To ensure CUI problem should not spark sudden surprise in plants, indeterminate factors that contribute to the deterioration of pipes subject to CUI should be recognized and taken care seriously. Operating temperature, type of environment, insulation type, pipe complexity and insulation condition of the pipes are the key factors that cause significant deterioration of pipes due to CUI. As per its varying nature, CUI is difficult to predict as it remains hidden beneath the insulation and gets growth in an ambiguous and abrupt manner. For such an uncertain and critical situation, fuzzy logic is a good choice to be deal with. Thus, in this study, CUI corrosion rate for insulated carbon steel piping systems has been predicted by fuzzy logic using API 581 data. Predicted CUI corrosion rates obtained by the developed fuzzy logic model are committing quite satisfactory results when comparing with API 581 published CUI corrosion rates. At the end of study, sensitivity analysis (SA) of CUI producing factors has also been performed. SA is showing the role of each CUI producing factor in terms of percentage, having participation for the cause of $1 \mathrm{~mm} /$ year CUI in pipes. The predicted CUI corrosion rates and SA will help inspection engineers for setting and delivering the risk-based inspection priority for insulated piping systems at their concerned plants.
\end{abstract}

\section{Introduction}

Corrosion under Insulation (CUI) is one of the main reasons of failure in insulated piping systems in oil and gas industries. The corrosion progresses in an insidious manner which unfortunately results in serious consequences [1]. Every year, there are many failure cases in these industries due to CUI of pipes and vessels around the world. However, only few of them are reported in literature [1]. In some cases, CUI represents more than one third of the corrosion failures in the chemical and offshore industries [3]. In 2003, a study made by Exxon Mobile Chemical indicated that the main cause of leaks in the chemical and refining industries is CUI and $81 \%$ of piping leaks were found in pipes having diameters smaller than

\footnotetext{
* Corresponding author: ainulakmar mokhtar@utp.edu.my
} 
4 inches [2]. They also reported that CUI contributed approximately $40 \%$ to $60 \%$ of the maintenance cost in oil and gas industry [4].

CUI is difficult to predict as it remains hidden beneath the insulation and gets growth in an abrupt, uncertain, and ambiguous manner [5]. Moreover, petroleum companies performing overhauling of their pipes or dealing with some unfortunate accidents with their piping systems, most of the times keeps their CUI data confidential due to their privacy matters [6]. Thus, very less field data is available in literature regarding CUI corrosion rates. The less availability of CUI corrosion rate field data and indefinite behavior of CUI on piping systems have made CUI a very complex and complicated problem. This is the reason CUI corrosion rate cannot be predicted using conventional methods.

Going through literature, it was found that fuzzy logic is a scientific tool appropriate for dealing with incomplete or vague information in the real world. Since CUI is regarded as a good example of a complex system in which fuzzy conditions can be developed and set [7]. Therefore, fuzzy logic has been chosen for prediction of CUI corrosion rates in this study. The benefit of fuzzy logic lies in its ability to include expert's experiences along with simulation of available data. The structure of the fuzzy logic model also allows easy calibration of the model to suit a plant condition or a complex process. This technique helps in lessening the dependency on the accurate data, permit modelling even when a complex process is partly understood, and eases the difficulties which usually arises as a result of the complex computations required by other traditional methods [8].

A detailed literature review was conducted, which revealed that many researchers have used fuzzy logic for the prediction of different types of corrosion for attaining the same objective, i.e. to alleviate the maintenance system of the industry with reference to the problem of corrosion. However, to lessen the length of this paper that literature review part has been omitted here. Further details for concerned literature review can be seen in [9] by the same authors.

\section{Development of CUI corrosion rate fuzzy logic model}

\subsection{CUI corrosion rate by API 581 for carbon steel pipes}

The relationship between corrosion rate of insulated carbon steel pipes with operating temperature and type of environment is described by American Petroleum Institute in its standard, API 581 as shown in Table 1 [10].

Table 1. CUI Corrosion rates in different types of environments and temperature as per API 581 [10].

\begin{tabular}{|c|c|c|c|c|}
\hline $\begin{array}{c}\text { Operating } \\
\text { Temperature } \\
\left({ }^{\circ} \mathrm{C}\right)\end{array}$ & \multicolumn{4}{|c|}{ Corrosion Rate (mm/year) in Different Types of Environments } \\
\cline { 2 - 5 } & Severe & Marine & Temperate & Arid/Dry \\
\hline-12 to -8 & 0 & 0 & 0 & 0 \\
\hline-8 to 6 & 0.076 & 0.025 & 0 & 0 \\
\hline 6 to 32 & 0.254 & 0.127 & 0.076 & 0.025 \\
\hline 32 to 71 & 0.254 & 0.127 & 0.076 & 0.025 \\
\hline 71 to 107 & 0.508 & 0.254 & 0.127 & 0.051 \\
\hline 107 to 135 & 0.254 & 0.127 & 0.025 & 0.025 \\
\hline 135 to 162 & 0.254 & 0.051 & 0.025 & 0 \\
\hline 162 to 176 & 0.127 & 0.025 & 0 & 0 \\
\hline More than 176 & 0 & 0 & 0 & 0 \\
\hline
\end{tabular}


Note:

- Interpolation should be applied for in-between temperature values.

The type of environment is classified into four categories which are severe, marine, temperate and arid based on the average rainfall. The severe area is defined as area having more than $1500 \mathrm{~mm} /$ year of rainfall, for marine area average rainfall is between 1000 to 1500 $\mathrm{mm} /$ year. For temperate area, the average rainfall is between 500 to $1000 \mathrm{~mm} /$ year, whereas, the average rainfall for arid area is less than $500 \mathrm{~mm} /$ year $[10,11]$. The plot of the relationships between corrosion rate with operating temperature and type of environment are shown in Figure 1 and Figure 2, respectively.

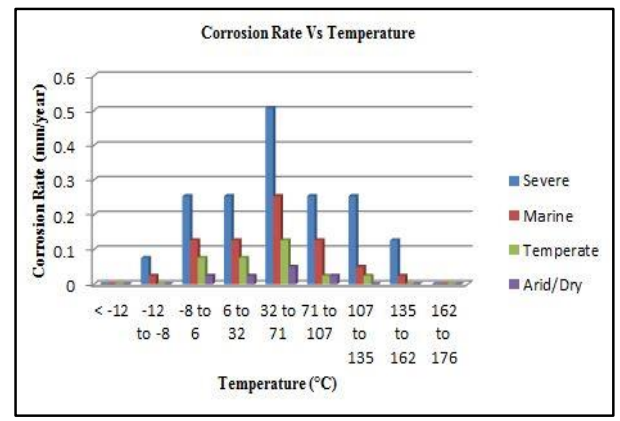

Fig. 1. Relationship between CUI corrosion rate of carbon steels and operating temperature

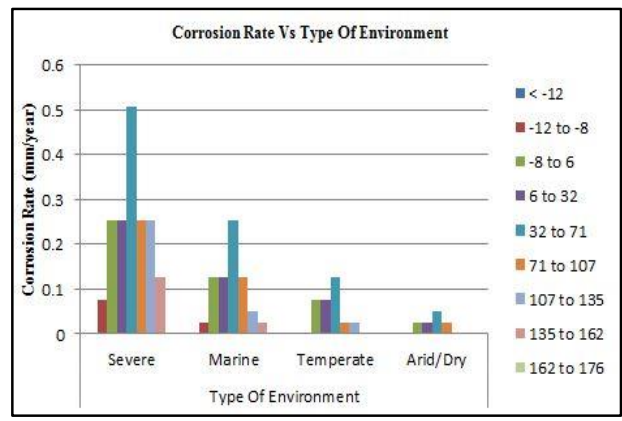

Fig. 2. Relationship between CUI corrosion rate of carbon steels and type of environment

Based on both graphs (Figure 1 and 2), it is shown that the highest corrosion rate for insulated carbon steel is $0.508 \mathrm{~mm} /$ year at the operating temperature range between $32^{\circ} \mathrm{C}$ to $71^{\circ} \mathrm{C}$ in severe environment. The trends of the corrosion rates are quite consistent for all temperature ranges except for the range of $32^{\circ} \mathrm{C}$ to $71^{\circ} \mathrm{C}$. For this temperature range the corrosion rate has been increased rapidly. The relationships between corrosion rate and the two potential corrosive factors i.e. temperature $\&$ environment cannot be described as a simple relationship as in a traditional method like a linear or an exponential curve etc. Therefore, fuzzy logic has been selected for this case.

\subsection{CUI corrosion rate fuzzy logic model}

A fuzzy logic model establishes the relationships between the output and inputs using a set of if-then rules as follow [9]: $R_{i}$ : If $x_{1}$ is $A_{i 1}$ and $x_{1}$ is $A_{i 2}$ and $\ldots x_{j}$ is $A_{i j}$, then $y$ is $B_{i}$, for $i=1, \ldots, n$ and $j=1, \ldots, r$ where $R_{i}$ represents the $i^{\text {th }}$ rule, $n$ is the total number of rules, $x_{j}$ are the input variables, $y$ is the only output variable, $A_{i j}$ are input fuzzy numbers defined in the input space and $B_{i}$ is the output space number defined in the output space. Thus, every rule is a local fuzzy relationship that maps a part of the multidimensional input space into a certain part of the output space. The fuzzy logic model was developed with five inputs/CUI producing factors i.e. operating temperature, type of environment, insulation type, pipe complexity, and insulation condition, while one output i.e. CUI corrosion rate. The assessment of CUI corrosion rate is often expressed vaguely by decision makers (inspectors, inspection and corrosion engineers, regulators) that often translated it into linguistic variables such as low, medium and high. This linguistic variable is qualitative, rather than quantitative. Based on the developed fuzzy logic model, the CUI corrosion rate can be determined quantitatively, if type of environment, operating temperature, insulation type, pipe 
complexity and insulation condition is provided. Figure 3 illustrates the fuzzy modelling accomplished by using the Fuzzy Logic Toolbox in MATLAB R2013a software.

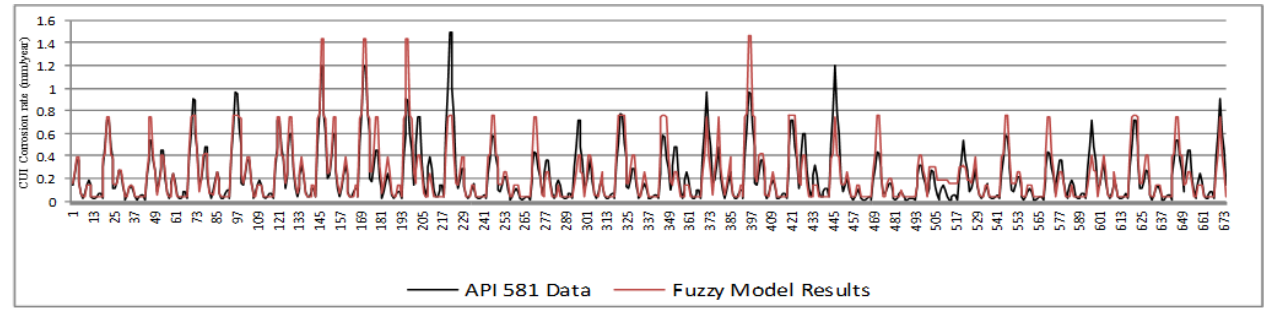

Fig. 3. Comparison between CUI corrosion rates given by API 581 and fuzzy logic model

\section{Sensitivity analysis for CUI producing factors}

Sensitivity Analysis (SA) was made to check the sensitivity of each individual CUI producing factor/input of the developed fuzzy logic model for the cause of CUI at the unit of $1 \mathrm{~mm} / \mathrm{year}$. Percentage increase/decrease in parameters of the fuzzy logic model was performed to carried out SA.

\section{Results and discussion}

\subsection{CUI corrosion rates obtained from developed fuzzy logic model}

The relationship of the inputs and the output was described using fuzzy logic by assuming that there is some uncertainty and imprecision data brought out, during fuzzy logic model development. The input spaces for both, inputs and output were based on the minimum and maximum values obtained from API 581 published data for carbon steel pipes. Table 1 shows CUI corrosion rate in different types of environments at different temperatures, when insulation type is perlite or none while pipe complexity and insulation condition are "average" with the assumption that piping system are supported on beams or such a configurations that do not allow proper coating [10]. The highest corrosion rate occurred at the temperature of $71^{\circ} \mathrm{C}$, in the severe environment. The overall results obtained through developed fuzzy logic model were much comparable with the API 581 data (root mean square error i.e. $\mathrm{RMSE}=0.007$ and mean absolute deviation i.e. $\mathrm{MAD}=0.076$ ). Table 2 shows comparison of API 581 data versus proposed fuzzy logic model results.

Table 2. Comparison between CUI corrosion rates given by API 581 and fuzzy logic model

\begin{tabular}{|c|c|c|c|c|c|c|c|c|}
\hline \multirow{3}{*}{$\begin{array}{c}\text { Operating } \\
\text { Temperature } \\
\left({ }^{\circ} \text { C) }\right.\end{array}$} & \multicolumn{6}{|c|}{ Corrosion Rate (mm/year) in Different Types of Environments } \\
\cline { 2 - 10 } & \multicolumn{2}{|c|}{ Severe } & \multicolumn{2}{c|}{ Marine } & \multicolumn{2}{c|}{ Temperate } & \multicolumn{3}{c|}{ Arid/Dry } \\
\cline { 2 - 10 } & API & Fuzzy & API & Fuzzy & API & Fuzzy & API & Fuzzy \\
& 581 & logic & 581 & logic \\
data & Results & data & Results & data & Results & $\begin{array}{c}581 \\
\text { data }\end{array}$ & $\begin{array}{c}\text { logic } \\
\text { Results }\end{array}$ \\
\hline-12 & 0 & 0.4822 & 0 & 0.1471 & 0 & 0.0787 & 0 & 0.0565 \\
\hline-8 & 0.152 & 0.6056 & 0.05 & 0.1864 & 0 & 0.0928 & 0 & 0.0472 \\
\hline 6 & 0.508 & 0.6549 & 0.254 & 0.2979 & 0.152 & 0.1455 & 0.05 & 0.0476 \\
\hline 32 & 0.508 & 1.2446 & 0.254 & 0.6334 & 0.152 & 0.3055 & 0.05 & 0.1005 \\
\hline 71 & 1.016 & 1.2194 & 0.508 & 0.6508 & 0.254 & 0.2873 & 0.102 & 0.0923 \\
\hline 107 & 0.508 & 1.1534 & 0.254 & 0.5504 & 0.05 & 0.1487 & 0.05 & 0.0832 \\
\hline
\end{tabular}




\begin{tabular}{|l|c|c|c|c|c|c|c|c|}
\hline 135 & 0.508 & 0.6603 & 0.102 & 0.1813 & 0.05 & 0.0559 & 0 & 0.0477 \\
\hline 162 & 0.254 & 0.5483 & 0.05 & 0.1046 & 0 & 0.0461 & 0 & 0.0459 \\
\hline 176 & 0 & 0.1489 & 0 & 0.0593 & 0 & 0.046 & 0 & 0.0459 \\
\hline
\end{tabular}

A valuable point that can be stressed out here from the developed fuzzy logic model is, at the operating temperature and type of environment where CUI is unlikely to occur; the corrosion rate is some numerical value. For instance, at $-12^{\circ} \mathrm{C}$ and $176^{\circ} \mathrm{C}$ in each type of environment, CUI corrosion rate given by API 581 is zero which is an unrealistic fact. It is claimed due to the two main reasons: (i) If (for example) an insulated pipe is in operation at $-12^{\circ} \mathrm{C}$ or $176^{\circ} \mathrm{C}$ for 20 years, then it is extremely difficult apparently or logically that it should not have CUI; (ii) According to statistics obtained from a local gas plant of Malaysia which has a marine environment, $2 \%$ of the operating temperatures of insulated pipes were found to be below $-12^{\circ} \mathrm{C}$ and $4 \%$ were found to be above $176^{\circ} \mathrm{C}$. The developed fuzzy logic model has a temperature range of $-40^{\circ} \mathrm{C}$ to $190^{\circ} \mathrm{C}$. It implies that the developed fuzzy logic model can also predict CUI corrosion rate at a temperature range of below or more than $12^{\circ} \mathrm{C}$ to $176^{\circ} \mathrm{C}$, for which API 581 has given zero CUI corrosion rate. Apart from prediction of CUI for the pipes that are under operation at operating temperature less than $-12^{\circ} \mathrm{C}$ or more than $176^{\circ} \mathrm{C}$, the CUI corrosion rate predictions for these ranges of operating temperatures can also be used for further analysis such as remnant life determination of pipes.

It should also be noticed that predicted CUI corrosion rate are slightly exceeding the API 581 data. These a little bit higher CUI corrosion rates are warmly admissible due to two main reasons; (i) API 581 data is experimental data which has been obtained under controlled situations [11]. Kurihara et al. [12] in his research has proved that field data subject to CUI corrosion rates is always higher than the API 581 published corrosion rates. When the facts and figures of his research work was deeply evaluated by the authors, its came to know that on an average, field data corrosion rates were 7\% more than API 581 published corrosion rates. (ii) Apart from selected CUI producing factors/ inputs which have been taken in this study, there are also some "other factors" which were also very slightly responsible for the cause of CUI. Coating quality, pipe location, type of coating, insulation jacketing condition, improper installations, inspection ports or plugs etc. are some examples of these "other factors". If these "other factors" are average or above average (in terms of worst scenario) in a case study, then definitely CUI for that specific case will be more than what published by API 581 data. Results obtained from developed fuzzy logic model are already satisfying those types of situations expectedly, hence are facilitating risk-based inspection program more appropriately.

Still, the developed fuzzy logic model does not include "other factors" that may affect the rate of CUI. The authors are currently investigating those factors to be integrated into the developed fuzzy logic model.

\subsection{Outcomes from sensitivity analysis}

SA of the developed fuzzy logic model was performed to observe "type of environment", "operating temperature", "insulation type", "pipe complexity", and "insulation condition" contribution for the cause of CUI corrosion rate which was the output of the developed fuzzy logic model. Figure 5 shows the behavior of CUI corrosion rate for all inputs of the developed fuzzy logic model, on $5 \%, 10 \%, 15 \%$, and $20 \%$ increment and decrement in parameters of the developed fuzzy logic model. The SA showed that type of insulation is the most sensitive parameter among all, followed by pipe complexity, type of environment, operating temperature and insulation condition. Each perturbed $(5 \%, 10 \%, 15 \%$, and $20 \%$ 
incremented/decremented) fuzzy logic model's results were compared with results generated by developed fuzzy logic model using Eq. (1).

$$
\% \text { Change }=\left|\frac{\text { Developed Fuzzy logic Model results }- \text { Perturbed fuzzy logic Model results }}{\text { Developed Fuzzy logic Model results }}\right| * 100
$$

It was observed that there was a maximum change in results (in terms of percentage) when there was a $20 \%$ decrement in parameters of developed fuzzy logic model for all input parameters except for input "Operating Temperature". For input "Operating Temperature" there was a maximum change in results when there was a $20 \%$ increment in developed fuzzy logic model as shown in Table 3 and Figure 4.

When putting these $\%$ changes of results on a scale of $100 \%$, sensitiveness of each input of the developed fuzzy logic model was found, in terms of percentage as shown in Table 3 and Figure 4. It can be concluded that for CUI corrosion rate of an insulated carbon steel piping system, type of insulation is $28.73 \%$, pipe complexity is $27.02 \%$, type of environment is $26.83 \%$, operating temperature is $13.02 \%$, while insulation condition is $4.38 \%$ responsible for the cause of $1 \mathrm{~mm} /$ year CUI.

Table 3. Maximum $\%$ Change in CUI corrosion rate with $\%$ contribution of each input parameters

\begin{tabular}{|c|c|c|}
\hline Input Parameters & $\begin{array}{c}\text { Maximum \% Change in CUI } \\
\text { corrosion rate }\end{array}$ & $\begin{array}{c}\text { \% Contribution of Input } \\
\text { Parameters }\end{array}$ \\
\hline Type of Insulation & 80.66 & 28.73 \\
\hline Pipe Complexity & 75.85 & 27.02 \\
\hline Type of Environment & 75.32 & 26.83 \\
\hline Operating Temperature & 36.57 & 13.02 \\
\hline Insulation Condition & 12.31 & 4.38 \\
\hline
\end{tabular}

The SA results imply that while maintaining an insulated piping system, a corrosion/inspection engineer should take most care for the factor "type of insulation", followed by pipe complexity, type of environment, operating temperature, and then insulation condition in a hierarchical way as shown in Figure 4.

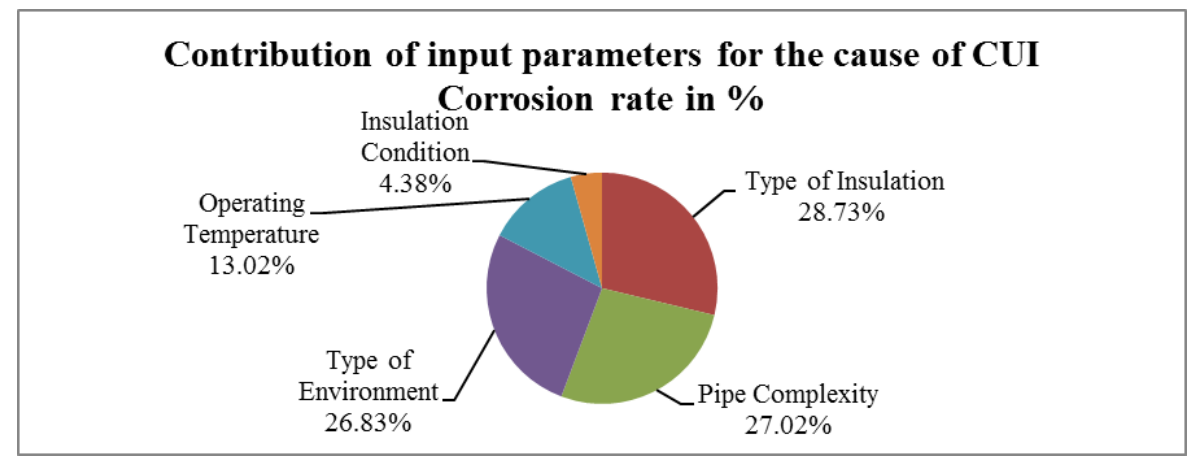

Fig. 4. Contribution of input parameters for the cause of CUI corrosion rate.

Rawaida et al. in her research [13] has experimentally proved that insulation type is the most significant factor for the cause of CUI, followed by operating temperature. She took in her consideration three CUI producing factors namely "insulation type", "operating temperature", and "cycle type", while investigating the most crucial factor for the cause of CUI by an experimental analysis using Taguchi method. In her another research [14], she has investigated three CUI producing factors namely "insulation type", "Elbows in pipe design", 
and "operating temperature", using logistic regression model. In this research she has revealed that insulation type is the most influential factor for the cause of CUI, followed by Elbows in pipe design (which is pipe complexity in this research), then operating temperature. Both of her researches are a compliment/confirmation for the SA results of the developed fuzzy logic model.

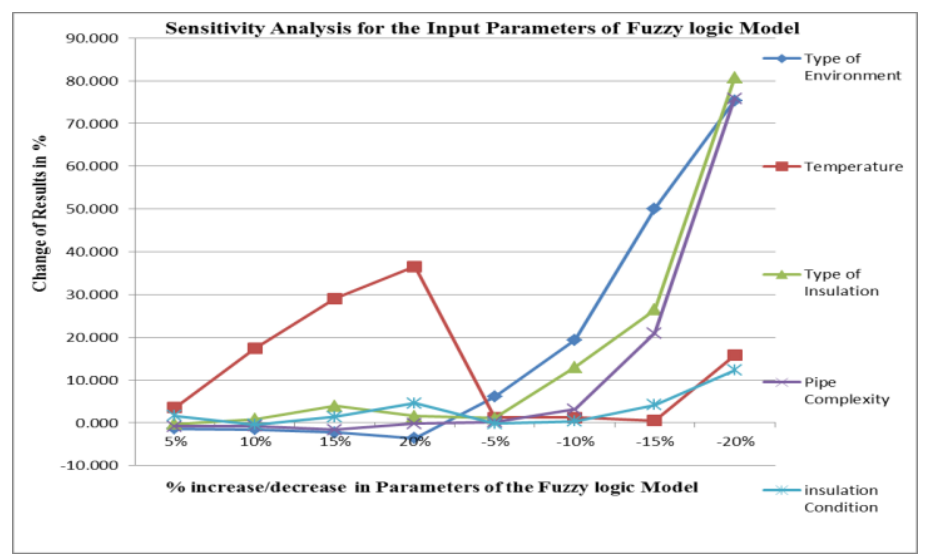

Fig. 5. Behavior of CUI corrosion rate for all input parameters

Figure 5 has opened a new horizon of knowledge and further research for future studies. For instance (in case of operating temperature), if operating temperature is increased up to $20 \%$, the CUI corrosion rate will also get increased by $36.57 \%$ when there will be a marine environment, type of insulation as pearlite or none, while pipe complexity and insulation condition as "average". Similarly, various precious results subject to CUI corrosion rates can be concluded for each $1 \%$ increment/decrement of, not only for "operating temperature" but also for the other inputs of the developed fuzzy logic model.

Similarly, further research can be performed to understand the behaviour of CUI corrosion rate (in terms of $\%$ increment/decrement of CUI). For example, what will be the CUI corrosion rate when there will be a severe environment, insulation type as calcium silicate, pipe complexity as "above average", while insulation condition as "below average" and so on. How there can be the least CUI corrosion rate in pipes having different conditions of CUI producing factors/ inputs of the fuzzy logic model. Authors are planning to investigate the different input factors and their different conditions for the development of a comprehensive fuzzy logic model in future studies.

\section{Conclusion}

CUI is an increasingly imperative problem for piping systems especially in oil and gas industries. Due to inconsistent nature of CUI, fuzzy logic was used for prediction of CUI corrosion rates. Afterward, SA of the input parameters of the developed fuzzy logic model was performed to know the percentage role of each of the input parameter, for the cause of CUI. It is expected that the conducted research work will be a beneficial tool for the plant management process and could be a guideline for inspection planning purpose with priority for the maintenance schedule.

\section{References}


1. O. Hills, "Corrosion: the hidden danger," World Pipelines, 5 (2005).

2. M. Lettich, "Is There A Cure for Corrosion under Insulation," Insulation Outlook Magazine (2005).

3. W. Wu, G. Cheng, H. Hu, Q. Zhou, "Risk analysis of corrosion failures of equipment in refining and petrochemical plants based on fuzzy set theory," Engineering Failure Analysis, 32 (2013).

4. A.A. Mokhtar, "Failure probability modeling for piping systems subject to corrosion under insulation," Ph.D. Thesis, Dept. Mech. Eng., UTP., Tronoh, Malaysia (2011).

5. M.M. Khan, A.A. Mokhtar, H. Hussin, "A neural-based fuzzy logic Model to determine corrosion rate for carbon steel subject to corrosion under insulation," Applied Mechanics and Materials (2015)

6. M.M. Khan, A.A Mokhtar, H.Hussin, "A fuzzy-based model to determine CUI corrosion rate for carbon steel piping systems", ARPN Journal of Engineering and Applied Sciences, 11, 22, November (2016)

7. A.A. Mokhtar, M. Che Ismail, "A fuzzy-Based model to determine corrosion rate for carbon steel subject to corrosion under insulation," paper presented at NACE, East Asia regional conference 2008, Kuala Lumpur, Malaysia (2008)

8. M. Singh, T. Markeset, "A methodology for risk-based inspection planning of oil and gas pipes based on fuzzy logic framework," Engineering Failure Analysis, 16 (2009)

9. M.M. Khan, A.A. Mokhtar, H. Hussin, "Prediction for corrosion under insulation subject to carbon steel pipes using ANFIS," ARPN Journal of Engineering and Applied Sciences, 11 (2016)

10. API 581, "Risk-Based Resource Document - Risk Based Inspection", American Petroleum Institute, Washington, DC (2000).

11. R.D. Kane, B. Chambers, "High temperature crude oil corrosivity: Where sulfur and naphthenic acid chemistry and metallurgy meet", Corrosion Solutions ${ }^{\circledR}$ Conference 2011 Proceedings, anticorrosionconference.com.

12. T. Kurihara, R. Miyake, N. Oshima, M. Nakahara, "Investigation of the actual inspection data for corrosion under insulation (CUI) in chemical plant and examination about estimation method for likelihood of CUI," Corrosion Engineering, 59 (2010).

13. N.R. Burhani, M. Muhammad, M. Che Ismail, M. Asmi Mahed, "An experimental analysis using Taguchi method in resolving the significant factors subject to corrosion under insulation", ARPN Journal of Engineering and Applied Sciences, 11, 20 (2016).

14. N.R. Burhani, M. Muhammad, A.A. Mokhtar, M. Che Ismail, "Application of Logistic Regression in Resolving Influential Risk Factors Subject to Corrosion Under Insulation”, Proceedings of the 2016 International Conference on Industrial Engineering and Operations Management, Kuala Lumpur, Malaysia, March 8-10 (2016) 